\title{
PLURALISMO JURÍDICO E DEMOCRACIA COMUNITÁRIO-PARTICIPATIVA NA BOLÍVIA: UMA PROPOSTA PARA REPENSAR A DEMOCRACIA
}

\section{Evilyn Scussel $^{1}$}

Resumo: O presente artigo aborda a crise do modelo democrático representativo, estruturado em razão da ascensão do capitalismo liberal. Analisa a possibilidade de instauração de um novo paradigma político, a partir das experiências recentemente ocorridas na Bolívia. Trata-se da democracia comunitária, que procede de tradições distintas da ocidental e emerge a partir de um processo de lutas de insurgência popular vivenciadas naquele país. Aponta-se o pluralismo jurídico como elemento de coesão para consolidar as vitórias democráticas ocorridas na Bolívia, contribuindo para a afirmação de uma genuína democracia por meio da ação dos sujeitos coletivos e do reconhecimento dos grupos comunitários.

Palavras-chaves: Democracia representativa; Crise; Democracia comunitária; Pluralismo jurídico.

\section{LEGAL PLURALISM AND COMMUNITY-PARTICIPATORY DEMOCRACY IN BOLIVIA: A PROPOSAL TO RETHINK DEMOCRACY}

\begin{abstract}
This article approaches the crisis of the representative democratic model, structured by the rise of liberal capitalism. It analyzes the possibility of establishing a new political paradigm, based on recent experiences in Bolivia. It is about community democracy, which comes from traditions different from the West and emerges from a process of popular insurgency struggles experienced in that country. Legal pluralism is pointed out as an element of cohesion to consolidate the democratic victories in Bolivia, contributing to the affirmation of a genuine democracy through the action of collective subjects and the recognition of community groups
\end{abstract}

Keywords: Representative democracy; Crisis; Community democracy; Legal pluralism.

\section{INTRODUÇÃO}

O Estado liberal, consolidado ao longo da modernidade, assumiu o centro único do poder e o monopólio de produção jurídica. Entretanto, tal modelo, na América Latina, não corresponde ao modo de viver o Direito e a Política experienciado pelas sociedades mestiças.

As mudanças recentes que vêm se desenvolvendo nos Estados latino-americanos, tal como ocorre na Bolívia, apontam para uma transição paradigmática marcada pela crise do

\footnotetext{
${ }^{1}$ Mestranda do Programa de Pós-Graduação em Direito (PPGD/UNESC). Graduada em Direito (UNESC). Bolsista pesquisadora UNIEDU/SC, membro do Grupo de Pesquisa Pensamento Jurídico Crítico Latino Americano e do Núcleo de Estudos em Direitos Humanos e Cidadania (NUPEC/UNESC). Advogada. E-mail: evilynscussel.adv@gmail.com.
} 
Estado e do modelo democrático clássico, demandando uma nova articulação político-jurídico e possibilitando amplo debate sobre a democracia.

É preciso, portanto, realizar um exame crítico acerca da crise do modelo constitucional de democracia representativa, que tem suscitado o debate acerca de novos paradigmas de legitimação, fundados na redefinição de conceitos, instituições e práticas democráticas para além do modelo liberal e com vistas à superação da exclusão estrutural presente nas sociedades latino-americanas.

Diante desse quadro, o presente artigo traz como problema central o seguinte questionamento: em que medida a realização da democracia comunitária prevista no texto constitucional boliviano favorece ou não a efetivação de uma pluralidade normativa?

Para tanto, a hipótese formulada é a de que há indícios para identificar na experiência política boliviana a possibilidade de construção de um novo modelo democrático comunitário a partir da realidade latino-americana e da adoção do Pluralismo Jurídico no texto constitucional.

Assim, o objetivo geral do trabalho consiste em demonstrar a aparente articulação entre a democratização comunitária na Bolívia e a adoção do pluralismo jurídico, que apresenta-se como o elemento de coesão para consolidar as vitórias democráticas dos povos e nações bolivianas.

Inicialmente, o artigo irá abordar a crise do modelo da democracia representativa diante o capitalismo, como parte de um processo de crise de legitimidade política que tem favorecido a emergência de práticas alternativas paralelas.

A segunda parte discutirá os avanços na perspectiva democrática que vem ocorrendo nos países latino-americanos, especialmente na Bolívia, a partir do reconhecimento de práticas comunitárias e da garantia de espaços aos povos indígenas, camponeses e comunidades tradicionais.

Por fim, o presente estudo buscará verificar se a adoção expressa do Pluralismo Jurídico no texto constitucional da Bolívia possibilita a consolidação da democracia comunitária, como pressuposto teórico válido para a concretização dos novos processos de resistência para combater as contradições da sociedade, visando a tomada de consciência e emancipação dos sujeitos oprimidos para a satisfação das necessidades humanas.

De maneira a cumprir com o objetivo proposto, adotou-se o método hipotéticodedutivo, com emprego de procedimento monográfico e das técnicas de pesquisa bibliográfica 
e documental, com consulta a livros, revistas e material coletado via internet sobre a crise da democracia representativa, sobre a democracia comunitária e sobre o pluralismo jurídico comunitário-participativo, com enfoque na Constituição da Bolívia (2009).

\section{DEMOCRACIA REPRESENTATIVA E SUA CRISE}

A partir das revoluções burguesas do século XVIII, que consolidaram o Estado liberal, emerge uma nova cultura acerca da democracia e do liberalismo, que vai definir os paradigmas políticos da modernidade. O Estado absoluto, que precedeu tais revoluções, conflitava com os interesses materiais da sociedade burguesa, que precisava de um Estado liberal com democracia representativa para se desenvolver (WOLKMER; FERRAZO, 2014).

Naturalmente, a burguesia revolucionário nos séculos XVII e XVIII surge visando a superação do absolutismo e a extinção dos privilégios da nobreza, tendo contribuído de modo decisivo para a elaboração da Constituição, em razão da necessidade de que fosse instaurada uma nova forma de regime político (RADAELLI, 2017).

Com a emergência da burguesia liberal capitalista, houve o distanciamento entre o âmbito formal e o material da democracia, agravando, assim, a crise democrática ocidental. $\mathrm{O}$ capitalismo liberal fez com que os espaços de participação democráticos fossem deslocados para o cenário da representação, “[...] consolidando o caráter burguês individualista conveniente à industrialização e à expansão dos mercados, e contribuindo, na dissimulação das injustiças sociais para mergulhar a democracia em profunda crise." (WOLKMER; FERRAZZO, 2014, p.202).

O Estado liberal monopolizou o poder e a prática política, operando uma separação entre os processos políticos e a sociedade, que passou a incidir somente através de seus representantes eleitos. O Estado moderno construiu e desenvolveu a cidadania dentro de um modelo da democracia representativa, dando origem à democracia formal, obstando assim o exercício da soberania do povo (COMPARATO, 2006).

Conforme Linera (2004) a democracia liberal constitui-se um modelo de cidadania instaurada nas sociedades que passaram por processos de individualização modernos e suplantaram a identidade coletiva. Consiste, assim, no produto da lógica industrial, que tem destruído os regimes de agregação de tipo tradicional. 
Concebida para as elites locais e para os grandes proprietários de terras, a "[ $\ldots]$ democracia burguesa "transplantada" do continente europeu para a periferia da América Latina, não era de fato, uma democracia que expressava os intentos e as tradições das comunidades autóctones." (WOLKMER; FREITAS, 2017, p. 26).

Considerando a tradição política liberal em que se baseia o modelo democrático representativo, é possível concluir que este foi arquitetado no marco do elitismo, de modo a garantir o afastamento entre representantes e representados e impedir o controle social e a efetiva participação dos cidadãos. Nesta perspectiva, tal configuração do modelo democrático tornou a democracia representativa totalmente vulnerável à corrupção e funcional ao status quo (SANTOS, 2016).

Para o professor de Coimbra (2016, p. 118) o surgimento do neoliberalismo fez emergir uma nova forma de democracia, de baixa intensidade, elitista e procedimentalista, a partir da "[...] eliminação da tensão entre democracia e capitalismo[...]" e pela "[...] retirada do Estado da regulação da economia e da liquidação da redistribuição social tornada possível no período anterior pelas políticas sociais.”.

Tais formas democráticas de "baixa intensidade" legitimam o neoliberalismo e transformam os direitos sociais em "escandalosos privilégios". Nesse contexto, “[...] os sistemas políticos estão a ser insidiosamente corrompidos para atender exclusivamente aos interesses das facções dominantes do capital.” (SANTOS, 2016, 162).

Como forma de enfrentamento à crise do modelo de democracia representativa Radaelli (2017, p. 286-287) afirma ser “[...] necessário um movimento paradoxal de enfraquecimento e fortalecimento do Estado.”, mediante a abertura para a ação popular e por meio da aplicação do princípio do "mandar-obedecendo".

$\mathrm{O}$ autor trata do resgate popular da democracia, primeiro, passando pela “[...] apropriação popular das instituições, operando-se a sua devida ressignificação na forma de uma institucionalidade popular-comunitária;" em segundo lugar, pela "[...] abertura para as formas de ação política que ocorrem fora e de forma paralela ao Estado, na forma de ação expressa nos referenciais de poder Dual [...]” (RADAELLI, 2017, p. 288).

Destaca, no mesmo sentido, a abertura do Estado para espaços políticos, instituições e regulações que funcionem fora dele, extra-institucionais, possibilitando a legitimidade das estruturas comunitárias. 
Esta nova configuração institucional popular e a consequente descentralização da atuação política do Estado são viabilizadas pelo Pluralismo Jurídico proposto por A. C. Wolkmer, como se verá a seguir.

O Estado moderno surge no marco da fundação da soberania, da despatrimonialização e da despersonalização do poder, criando assim o espaço público institucional, capaz de incorporar toda a diversidade social em sua multiplicidade e com suas contradições. Neste contexto, o sistema representativo surge como instrumento para atenuar a distância entre os indivíduos e o Estado abstrato. Esta abstração estatal decorre da "[...] separação, autonomização e especialização de um centro de poder em relação ao corpo de cidadãos." (BERCOVICI, 2002, p. 3).

Para Bercovici (2002, p.4) “A identificação entre os desejos dos representados e as atitudes dos representantes não mais responde à grande variedade de relações representativas que ocorrem nos sistemas políticos contemporâneos."

Ressalta-se, ademais, que o poder representativo se legitima não porque expressa um consenso real, mas porque permite uma antecipação bem-sucedida do consenso presumido dos representados. Sendo assim, a representação política é tida como um conjunto de ações capaz de conferir legitimidade ao poder. "O representante exerce um mandato não apenas referente ao que lhe foi conferido, mas também ao que não lhe foi. O representante foi eleito num procedimento institucionalizado, portanto é digno de representar o representado." (BERCOVICI, 2004, p. 15-16).

A democracia representativa, segundo os aportes de B. S. Santos (2016), consiste no regime político cujo poder democrático dos cidadãos é concentrado nos representantes eleitos, que o exercem de forma mais ou menos autônoma.

A autonomia, ainda que possa ser tomada como um pressuposto para que tal modelo democrático se concretize, representa um fator de tensão constante entre representantes e representados, fazendo com que estes, muitas vezes, não se reconheçam nos decisores políticos.

Daí emerge o que B. S. Santos (2016) denomina patologia da representação e de participação, o que implica uma crítica da teoria politica liberal em que assenta as bases a democracia representativa.

No tocante à crise da representação, Wolkmer (2014) salienta que é parte de um processo de esgotamento da própria institucionalidade vigente, expressa pela perda de eficácia 
e confiabilidade nos partidos políticos, na administração pública, no legislativo e no judiciário. Ora, na realidade latino-americana, a democracia chega a ser realmente representativa, mas “[...] uma delegação engedrada e manipulada por lideranças de tradição elitista”. (WOLKMER, 2014).

Ao tratar da crise dos partidos políticos, Campilongo (1987, p. 97) salienta que esta expressa a relação destes com a sociedade. "Reflete sua incapacidade de filtrar as demandas sociais e transformá-las em decisões políticas".

Segundo Moraes e Streck (2013) o modelo de democracia representativa, como alternativa possível em uma sociedade que se complexificou, se tornou um instrumento incapaz de responder adequadamente a todos os anseios sociais. Segundo os autores, a fragilização do espaço público da política e sua economicização, geram a tendência ao desaparecimento de opções reais de escolha, pressuposto da democracia representativa, que traz como consequência uma apatia da população pelas eleições.

Com o advento da globalização, houve a redução dos espaços políticos, e conferiu-se à constituição o papel de representante dessa esfera. A constituição e a democracia passam a ser definidas como estruturas processuais capazes de restaurar as bases da legitimidade liberal democrática (BERCOVICI, 2004).

Para Andrade (1993) a democracia liberal representativa está aliada ao crescimento e estabelecimento do capitalismo como sistema hegemônico na economia, para a legitimação política dos detentores do capital: a democracia liberal é, antes de tudo, liberal e o liberalismo se faz democracia somente na medida em que este regime é o que lhe pode oferecer a garantia à liberdade de propriedade. Nas palavras da autora:

[...] porque a concepção liberal de cidadania expressa a supervalorização da representação em detrimento da participação política, pois a participação política do cidadão implica a necessidade de associação (o que fere o pressuposto liberal de homem atomizado) e implica, também, a politização da sociedade civil (o que fere o pressuposto liberal da sociedade civil com o lugar destinado às relações econômicas privadas), significando introduzir a política num lugar onde é indevida nesse modelo (p11).

Ademais, a democracia ocidental e sua identificação com o voto, durante seu processo de construção histórica, acarretou a redução dos espaços de construção democrática, fazendo-a padecer de um "vício mais profundo e perigoso para a democracia plena: a 
identificação entre liberdade individual e liberdade de mercado, como fruto do sistema de economia capitalista" (WOLKMER; FERRAZO, 2014, p.12).

Partindo da análise de Wolkmer (2014, p.10), cabe ressaltar que a crise do modelo democrático clássico não implica a exclusão da representação, mas a sua combinação com a “[...] participação dos sujeitos coletivos emergentes, corporificadores de uma cidadania comunitária e intercultural”.

Este processo de transição paradigmática e a crítica ao funcionamento do Estado deflagra, por sua vez, a busca por alternativas na construção de uma ordem democrática e legítima. Consequentemente, no tempo presente, revelam-se nas mais diversas esferas da vida social “[...] resistências vigorosas ao avanço do neoliberalismo [...]”, como por exemplo, “[...] as três formas de democracia consagradas na Constituição da Bolívia de 2009: representativa, participativa e comunitária.” (SANTOS, 2016, p. 165).

\section{DEMOCRACIA COMUNITÁRIA: PROPOSTA PARA UMA NOVA RACIONALIDADE POLÍTICA}

Como ocorre tradicionalmente na América Latina nas mais variadas vertentes, o direito e as instituições jurídicas de origem do colonizador europeu e necessitam passar por um processo de democratização nesse momento de transição paradigmática (FAGUNDES, 2015).

Diante da crise do modelo de democracia representativa e do empoderamento que emana da tomada de consciência pelos povos latino-americanos, cria-se a possibilidade de instaurar-se uma nova racionalidade política.

É possível vislumbrar neste cenário, a partir da experiência política que vem se desenvolvendo na América Latina, uma nova democracia que procede de tradições distintas à ocidental e emerge partir de um processo de lutas de insurgência popular que vêm ocorrendo no país. Neste contexto, irrompe um novo paradigma político, para além dos limites da racionalidade burguesa eurocêntrica.

Trata-se da democracia comunitária, pautada no novo constitucionalismo pluralista latino-americano, previstos nas novas cartas políticas e materializada nas práticas concretas de 
países como a Bolívia e o Equador, que estão vivenciando este constitucionalismo pluralista (WOLKMER; FERRAZO, 2014).

A Bolívia, especificamente, atravessa um período de transição paradigmática em que não prevalece hegemonicamente nenhum modelo político. O Estado, através de sua Carta Constitucional, reconhece as formas de democracia representativa, participativa e comunitária.

A crise do processo democrático clássico abre a possibilidade para uma nova democracia, fruto das tradições dos povos colonizados e associada a uma forma de organização política própria dos povos originários e em oposição ao modelo estatal monocultural e monocivilizatório, que historicamente tem impedido a estabilidade, pois representa uma "[...] mera parcialidad, como una parte de un todo que no logra sintetizar". (LINERA, 2004, p. 5).

Tais formas de organização política baseadas em hábitos, práticas e modo comunitários, partem de técnicas de democracia e cidadania regidas por parâmetros morais e políticos distintos dos valores liberais e efetivam-se a partir de associações, assembleias em âmbito local e regional. (LINERA, 2004).

Villoro (2006) chama atenção para a impossibilidade de transplantar a democracia comunitária em seu modo originário, pois tal sistema de convivência política insere-se em um âmbito social diverso, em comunidades pequenas e de dimensões reduzidas, em que todos se conhecem, se comunicam e podem reunir-se facilmente para buscar um acordo coletivo.

Para além destas constatações, Villoro (2006) afirma que contemporaneamente as sociedades se complexificaram e as democracias modernas passaram a abarcar múltiplas formas de vida. Assim, a adoção da democracia comunitária implica a sua adaptação às sociedades modernas.

A proposta de "renovação" da democracia comunitária concebida por Villoro (2006) passa pela adoção de valores do republicanismo ${ }^{2}$. Este projeto, através da junção dos valores das democracias tradicionais com os da república moderna, daria lugar a uma nova versão do republicanismo, modelo apto a enfrentar a atual crise do Estado Moderno.

Examinando o projeto apresentado pelo filósofo mexicano, é possível elencar as principais características deste novo modelo democrático: a) a revalorização das formas de

\footnotetext{
${ }^{2}$ Para Villoro (2006) republicanismo consiste em uma corrente filosófica que opõem o governo republicano às formas de governo autoritário e oferece ama conceituação de democracia distinta à do liberalismo clássico.
}

Revista Brasileira de Filosofia do Direito| e-ISSN: 2526-012X| Porto Alegre | v. 4 | n. 2 | 
vida comunitária e o fomento ao seu surgimento em diferentes esferas, alçando a comunidade à base da democracia; b) a delegação das competências políticas e recursos econômicos às células dos municípios (comunidades e municípios); c) a aproximação entre o poder político e o povo "real", por meio de procedimentos de democracia participativa ou "radical" e garantia de que os mandatários eleitos "mandem obedecendo" e prestem contas de sua gestão aos eleitores; d) a implantação de procedimentos de democracia direta em âmbitos sociais reduzidos e transmissão de competências aos poderes locais, lançando as bases de um Estado plural, cujo princípio norteador consistiria no direito à solidariedade entre todos; e) a promoção do bem comum, que não parte da imposição de uma concepção de bem comum, tampouco da neutralidade do ente estatal, mas da busca pela cooperação, solidariedade, reconhecimento recíproco e ajuda mútua entre todas as entidades sociais, tendo como condição precípua a não exclusão.

Por certo, a democracia comunitária,

\begin{abstract}
Nos hablan de sociedades que se niegan a la exclusión, en las que todos tienen su lugar y todos son objeto de conside- ración. Nos recuerdan, sin declararlo expresamente, que la democracia es el poder del pueblo real, que se ejerce allí donde los hombres viven y trabajan y no puede ser sustituida por un grupo de representantes que los suplantan. Nos hacen patente la posibilidad de una vida social donde la solidaridad en la realización de un bien común puede prevalecer sobre los mezquinos intereses individuales. (VILLORO, 2006, p. 11).
\end{abstract}

Tal modelo, conforme os aportes de Villoro (2006) não visa a extinção do modo democrático representativo, contudo, diversamente do modelo liberal, busca o acordo coletivo por meio do diálogo e através da participação de todos os membros da comunidade.

Para Paco (2013) a "gestão política comum" é exercida pela coletividade, por meio da "deliberação coletiva", tomada como "fonte do poder". Neste sentido, a coletividade reveste-se do poder de decisão sobre assuntos que dizem respeito à população e os mecanismos de gestão do "comum" se constroem a partir de acordos entre sujeitos concretos, que compartilham a mesma realidade. Trata-se de um modelo em que o poder é administrado diretamente pelo povo e a soberania é indelegável.

$\mathrm{Na}$ Bolívia a unidade de deliberação corresponde às circunscrições eleitorais, com a participação de autoridades e representantes territoriais e setoriais, ou ainda de associações coorporativas funcionais, sejam elas de zonas, bairros ou distritos na cidade ou autoridades originárias campesinas e indígenas de cada comunidade nas áreas rurais. (PACO, 2013). 
Ressalta o autor boliviano que para conferir maior operacionalidade prática, cada sociedade deve construir a instância de deliberação conforme suas particularidades e potencialidades.

No âmbito da democracia comunitária a representação não monopoliza o direito de decidir e o representante limita-se a expressar e operacionalizar a decisão adotada pela coletividade. Neste sentido, “[...] el que "manda porque obedece”, porque se sujeta a lo que es la decisión común o sea el resultado de la deliberación colectiva; y sólo en tal sentido adquiere su calidad de representante”. (PACO, 2013, p. 83).

A política, por sua vez, busca de modo concreto o equilíbrio entre as capacidades e as necessidades sociais e expressa o dever e o serviço à comunidade. Tem-se, assim, a "posse" do poder e não a sua "propriedade" e esse, diversamente do modelo de democracia liberal, não concentra-se em determinados indivíduos ou grupos, tampouco se adquire por faculdades próprias dos sujeitos. (PACO, 2013).

No tocante ao modelo de democracia adotado na Constituição da Bolívia de 2009, Wolkmer e Freitas (2017) aduzem tratar-se de um modelo híbrido complementar, com a possibilidade de três formas de participação democrática: representativa, que vem complementada por mecanismos de democracia direta e participativa, com equivalência de condições entre homens e mulheres, e a democracia comunitária.

Dispõe o artigo 11 da referida carta constitucional:

\footnotetext{
Artículo 11.

La República de Bolivia adopta para su gobierno la forma democrática participativa, representativa y comunitaria, con equivalência de condiciones entre hombres y mujeres.

I. II. La democracia se ejerce de las siguientes formas, que serán desarrolladas por la ley:

1. Directa y participativa, por medio del referendo, la iniciativa legislativa ciudadana, la revocatoria de mandato, la asamblea, el cabildo y la consulta previa. Las asambleas y cabildos tendrán carácter deliberativo conforme a ley.

2. Representativa, por medio de la elección de representantes por voto universal, directo y secreto, conforme a ley.

3. Comunitaria, por medio de la elección, designación o nominación de autoridades $y$ representantes por normas y procedimentos propios de las naciones y pueblos indigena originario campesinos, entre otros, conforme a ley.
}

Nessa configuração, na Bolívia optou-se pela reorganização do Estado em bases mais democráticas, visando fórmula moderna de "para cada Estado uma Nação", bem como do sistema representativo de democracia, “[...] o qual teria que prever sistemas de participação 
adequada aos novos sujeitos coletivos na garantia de que o novo modelo político-institucional seria implementado." (WOLKMER; FREITAS, 2017, p. 14).

Em suma, o protagonismo dos movimentos indígenas na Bolívia traduziu o “[...] reconhecimento de um terceiro tipo de democracia, a comunitária, constituída pelos processos de discussão e deliberação ancestrais das comunidades indígenas." Tal reconhecimento, redundou na consagração dos três tipos de democracia na nova Constituição da Bolívia: a representativa, a participativa e a comunitária. (SANTOS, 2016, p. 120).

Destaca-se no texto constitucional da Bolívia, mecanismos de democracia direta, de revogação de mandato, assembleias, conselhos e consultas, institutos vinculados à democracia comunitária que prevê a eleição, nomeação ou designação de autoridades representantes, tendo por base as regras e os procedimentos das nações indígenas e comunidades tradicionais.

Para Médici (2010, p.14) esta nova configuração democrática propicia uma autentica reinvenção política:

El principio organizativo de "demo diversidad" (Santos, 2007:47), es decir, el reconocimiento constitucional de una pluralidad de prácticas democráticas directas y por delegación, significa la posibilidad de una real igualación política a partir de la superación de la estructura mono organizativa del Estado que históricamente ha reconocido e instituido como únicas formas del ejercicio legítimo de democracia y ciudadanía a las provenientes de la democracia representativa liberal y minoritaria.

Naturalmente, o processo de consolidação da democracia comunitária na Bolívia enfrenta desafios na medida em que opõe-se à lógica dominante. Deste modo, conforme aponta Radaelli (2017, p. 180) “[...] é preciso uma aposta radical na reconstrução do aparato estatal por elementos para-estatais, com isso a democracia representativa é oxigenada pela democracia direta, mais especialmente pela Democracia Comunitária”.

\section{PluRALISMO JURídico COMO PROJETO DE CONSOLIDAÇÃo DA DEMOCRACIA COMUNITÁRIA NA BOLÍVIA}

Ante a necessidade de reconstrução do aparato estatal como pressuposto a uma profunda e significativa democratização comunitária na Bolívia, o pluralismo jurídico apresenta-se a partir do reconhecimento de direitos nascidos de práticas ancestrais. Neste 
âmbito, propõe-se o pluralismo jurídico comunitário participativo, cuja principal característica é a negação de que o Estado seja a fonte única do poder e exclusiva de todo o direito.

Nas sociedades periféricas latino-americanas, marcadas pelo intervencionismo estatal e pela exclusão faz-se necessária a adoção de um pluralismo jurídico de características participativas, "inserido nas contradições materiais e nos conflitos sociais" através da adoção de "práticas cotidianas insurgentes" e pela "auto-regulação" do próprio poder societário". A incidência desta teoria implica o emprego de uma "[...] dinâmica interativa e flexível de um espaço público aberto, compartilhado e democrático.” (WOLKMER, 1991, p. 171).

Wolkmer define o pluralismo jurídico como sendo:

[...] a multiplicidade de práticas jurídicas existentes num mesmo espaço sóciopolítico, interagidas por conflitos ou consensos, podendo ser ou não oficiais e tendo sua razão de ser nas necessidades existenciais, materiais e culturais (2001, p.219).

Para Martinez (2017), o pluralismo jurídico teorizado por Wolkmer parte do pressuposto de que o monopólio estatal na produção jurídica é incapaz de contemplar corretamente a existência de desvantagens próprias de grupos sociais particulares e de perceber a relatividade da ideia de justiça.

A partir dos aportes de Jacques Vanderlinden, Wolkmer (1991) aponta as duas principais causas do pluralismo jurídico como sendo a ineficácia e a injustiça do modelo da "unicidade do direito." Parte do pressuposto de que o modelo da unicidade é incapaz de contemplar corretamente a existência de desvantagens próprias de grupos sociais particulares e de perceber a relatividade da ideia de justiça.

O pluralismo jurídico demonstra de modo amplo a força e a autenticidade de múltiplas manifestações normativas não estatais e revela toda uma rica produção legal informal e insurgente a partir de condições materiais, lutas sociais e contradições classistas e interclassistas.

Não se trata propriamente de um uso alternativo de direito, que se relaciona diretamente com o direito oficial estatal, mas de um processo de construção de outras formas jurídicas.

Consequentemente, “[...] el pluralismo puede tener como meta, prácticas normativas autónomas y auténticas generadas por diferentes fuerzas sociales o comunidades culturales 
linguísticas plurales y complementarias reconocidas, incorporadas o controladas por el Estado." (WOLKMER, 2016, p. 12).

Conforme Wolkmer (2001, p.234-235) o projeto pluralista de emancipação apresenta duas condições. A primeira refere-se à estratégia de efetividade material, que compreende os sujeitos coletivos de juridicidade e a estrutura da satisfação das necessidades humanas. Por outro lado, a segunda consiste na estratégia de efetividade formal, que abrange os procedimentos na prática e na teoria. A prática é desenvolvida através de ação coletiva, "que implica em reordenar a sociedade para uma política de democracia decentralizadora e participativa" e de ação individual, através da chamada "ética de alteridade". A teoria, por sua vez, busca "construir processos de racionalidade comprometidos com a autonomia e a emancipação da essência humana".

Com o intuito de ambientar a discussão, cumpre diferenciar um pluralismo jurídico como projeto conservador, de uma proposta do pluralismo jurídico como um projeto de legalidade alternativa e contra hegemônica.

O pluralismo jurídico como projeto conservador, expressão do capitalismo global e do neoliberalismo, está relacionado à descentralização da administração da justiça, desregulamentação dos direitos sociais e ao reconhecimento de normas suprabnacionais, avindas de negociações e acordos comerciais. Consiste em estratégia para os propósitos do "neocolonialismo" e "neoliberalismo" dos países de capitalismo central avançado, excluindo os países emergentes periféricos do sul global. (WOLKMER, 2016).

Nesse sentido, para alcançar seus objetivos, o pluralismo conservador impossibilita a organização das tradições comunitárias e impede a verdadeira participação das comunidades.

Portanto, o pluralismo jurídico conservador se contrapõe radicalmente ao pluralismo jurídico proposto por A. C. Wolkmer.

A proposta do pluralismo jurídico como um projeto contra hegemônico está associada a comunidades e setores populares e resulta de lutas sociais e de formas autônomas e alternativas de práticas sociais comunitárias. Consiste em estratégia democrática para enfrentar os conflitos que marcam as sociedades latino-americanas, através do estimula à participação múltipla dos segmentos populares e dos novos movimentos sociais. (WOLKMER, 2016). 
Para o autor, "Tratase de un Pluralismo Jurídico transformador que constittuye su legitimidad desde el poder comunitario, de los nuevos actores colectivos subalternos y de sus necesidades básicas[...]". (WOLKMER, 2016, p. 14).

Assim, consiste em um:

\begin{abstract}
Modelo aberto e democrático, privilegiando a participação direta dos sujeitos sociais na regulação das instituições chave da sociedade e possibilitando que o processo histórico se encaminhe pela vontade e controle das bases comunitárias. Reitera-se nessa tendência, antes de mais nada, a propensão segura de se visualizar o Direito como um fenômeno resultante de relações sociais e valorações desejadas, de se instaurar uma outra legalidade, a partir da multiplicidade de fontes normativas não obrigatoriamente estatais, de uma legitimidade embasada nas 'justas' exigências fundamentais de atores sociais e, finalmente, de encarar a instituição da sociedade como uma estrutura descentralizada, pluralista e participativa. (WOLKMER, 2001, p. 69).
\end{abstract}

Nesse contexto, a proposta conforme teorizada por A. C. Wolkmer caracteriza-se pela combinação dos seguintes pressupostos: a) legitimidade de novos sujeitos sociais; b) fundamentação na justa satisfação de necessidades humanas; c) democratização e descentralização de um espaço público participativo; d) defesa pedagógica de uma ética da alteridade; e) consolidação de processos conducentes a uma racionalidade emancipatória.

Em suma, o pluralismo jurídico comunitário participativo lança as bases para a consolidação de um modelo democrático coerente para a América Latina.

Fazendo uma análise da democracia realizada comunitariamente, através de seus mecanismos de participação direta, indireta e comunitária, bem como da abertura estatal para a deliberação popular, é possível verificar que tal modelo coaduna-se com a vertente do pluralismo jurídico de tipo comunitário-participativo, contemplando o pressuposto de democratização e descentralização do espaço público participativo.

As novas subjetividades coletivas, elemento da teoria formulada por A. C. Wolkmer, configuram-se como atores para a construção de uma democracia comunitária, propondo, na perspectiva de Radaelli (2017) uma inovadora dinâmica política e uma nova agenda social, desafiando, assim, o paradigma liberal individualista.

Esses novos sujeitos de direito $^{3}$, segundo Wolkmer (2001, p. 240) são identidades coletivas dotadas de consciência, mais ou menos autônomas, provenientes de diversas esferas

\footnotetext{
${ }^{3}$ Tais sujeitos não se confundem com os sujeitos individualistas, abstratos e universais de matriz liberalburguesa, regulados pelas leis do mercado e inseridos do processo de capital e de trabalho. (WOLKMER, 2014, p. 11).
} 
sociais, com capacidade de autoafirmação e auto-organização, interligadas por modos de vida permeados por interesses comuns e por conflitos e lutas que expressam privações e necessidades por direitos, legitimando-se como um poder transformador e instituidor de uma sociedade democrática, descentralizada e com intensa participação.

Esta nova concepção de identidade coletiva é produto da consciência da condição marginalizada do ser latino-americano, cujo engajamento visa a satisfação das necessidades humanas. Assim, o Pluralismo jurídico comunitário-paticipativo lança as bases para a construção da democracia comunitária, por meio do reconhecimento dos novos sujeitos coletivos em suas lutas pela satisfação de suas necessidades existenciais.

Para Wolkmer (2001, p. 175) é indiscutível que a "descentralização" acaba tornandose condição necessária para impulsionar a dinâmica interativa da própria "participação". Ora, enquanto a cultura monista se desenvolve numa tradição de procedimentos representativos, o pluralismo jurídico comunitário participativo propicia mais diretamente a prática da participação de base.

O poder local é o nível mais descentralizado do poder estatal, organizado e articulado por relações que mais diretamente tem influência da sociedade e dos interesses advindos das forças sociais. Assim, é necessário “[...] viabilizar as condições para a implementação de uma política democrática que direcione e ao mesmo tempo reproduza um espaço comunitário descentralizado e participativo." (WOLKER, 2001, p.249).

Na análise de Radaelli (2017, p. 221) surge neste contexto um sujeito coletivo, cuja satisfação das necessidades humanas implica a inter-relação comunitária. Nestes termos, o Pluralismo Jurídico Comunitário Participativo “[...] aponta para o reconhecimento e afirmação funcional das vivências expressas em uma comunidade ${ }^{4} . "$

A nova configuração de democracia realizada comunitariamente, na concepção de Radaelli (2017) “[...] o povo passa a incidir diretamente, colabora para que o caráter delegativo, assumido nas democracias atuais, seja superado por uma ação representativa que, de fato, torne o povo presente na ação estatal.” (RADAELLI, 2017, p. 221).

Vê-se, assim, a retomada do conceito de comunidade, como a "pluralidade de interações das formas de vida" associadas em torno das necessidades humanas essenciais, cuja

\footnotetext{
${ }^{4}$ Para fins deste estudo, adotou-se a concepção de comunidade como "[...] aglomerado social com características singulares, interesses comuns e identidade própria, que, embora inseridos num aspectro de relações pulverizadas por consenso/dissenso, interligam-se por um lastro geográfico especial, coexistência ideológica e carências materiais." (WOLKMER, 2001, p. 293).
} 
ação transformadora passa pela adoção de práticas comunitárias, o que "[...] implica na ampliação do processo democrático fundado na "descentralização", na "participação de base" e na redefinição de cidadania." (WOLKMER, 2014, p.12).

No tocante às condições formais, (reordenação do espaço público), verificam-se duas medidas consolidadas na Constituição da Bolívia: o reconhecimento do pluralismo jurídico e o reconhecimento de uma terceira forma de democracia: a democracia comunitária. Para Wolkmer (2001, p. 249 e ss.) a reordenação política do espaço público implica democracia, descentralização e participação. (WOLKMER; FERRAZO, p. 223).

Cumpre salientar que o novo paradigma não visa superar a representação, mas avançar e ampliar tal modelo a partir da reordenação do espaço público, “[...] redefinido e orientado pela insurgência de novos atores sociais, a dinâmica do "modo de vida", passando por um processo de descentralização democrática, participação na tomada de decisões e controle comunitário [...]”. (WOLKMER, 2014, p. 2).

O pluralismo jurídico teorizado por Wolkmer compreende ainda dois elementos formais a ética concreta da alteridade e a racionalidade emancipatória. A ética concreta da alteridade não limita-se à abstrações ou formalismos, mas “[...] constrói-se a partir do outro, em suas lutas cotidianas, seus conflitos e suas necessidades fundamentais[...]", constituindose como verdadeira "expressão de valores emergentes". Tais jurisdições autônomas constituem-se espaço de concretização destas novas categorias teóricas propostas e redefinem politicamente o espaço público na Bolívia. (WOLKMER; FERRAZO, 2015, p. 223).

A racionalidade emancipatória, pressuposto na adoção do pluralismo jurídico comunitário participativo, rompe com a racionalização e mercantilização da vida moderna que passa a pautar-se em valores cosmocêntricos e transindividuais que partem da vida concreta, considerando os interesses e necessidades da pluralidade de ações humanas (WOLKMER, 2001).

Deste modo, o pluralismo jurídico vai se configurando no Estado boliviano e contribuindo para a consolidação de um processo de democratização, operando como indutor do modelo de democracia comunitária por meio da ação dos sujeitos coletivos e do reconhecimento dos grupos comunitários. (RADAELLI, 2017).

\section{CONCLUSÃO}


A partir das revoluções burguesas do século XVIII, que consolidaram o Estado liberal, emerge uma nova cultura acerca da democracia e do liberalismo, que vai definir os paradigmas políticos da modernidade e da democracia moderna.

Contudo, com a emergência da burguesia liberal capitalista, houve o distanciamento entre o âmbito formal e o material da democracia, que desencadeou a crise democrática ocidental. O capitalismo liberal fez com que os espaços de participação democráticos fossem deslocados para o cenário da representação, contribuindo para a dissimulação das injustiças sociais, fazendo a democracia mergulhar em profunda crise.

O modelo de democracia representativa, como alternativa possível em uma sociedade que se complexificou, se tornou um instrumento incapaz de responder adequadamente a todos os anseios, ante a fragilização do espaço público da política e sua economicização, que geram o desaparecimento de opções reais de escolha, pressuposto da democracia representativa. Como consequência, o modelo representativo passou a enfrentar momento de profunda crise que se constata na perda de confiança nos partidos políticos e na eficácia dos poderes do Estado, agravada pela manipulação do poder delegado aos representantes dos países.

Desta crise emerge uma nova forma de democracia, a partir da experiência política que vem se desenvolvendo na América Latina, que procede de tradições distintas à ocidental e emerge de um processo de lutas de insurgência popular que vêm ocorrendo no país. Neste contexto, irrompe um novo paradigma político, para além dos limites da racionalidade burguesa eurocêntrica, viabiliza a tomada de decisões políticas desde as bases da sociedade e não desde as elites, tal como o direito pugnado pelo pluralismo jurídico teorizado por A. C. Wolkmer.

A partir da emergência deste modelo democrático, produto da consciência da condição marginalizada do ser latino-americano, cujo engajamento visa a satisfação das necessidades humanas, visualiza-se a grande vitória das nações e povos indígenas originários campesinos ao ver positivado o pluralismo jurídico comunitário. Trata-se de um grande avanço em direção à plurinacionalidade.

Enfim, a tarefa que se tem em vista é possibilitar o exame crítico acerca da crise do modelo constitucional da representação, que implica na busca por alternativas. Assim, ainda que não se pretenda apresentar o pluralismo jurídico comunitário-participativo como derradeira solução para o esgotamento do modelo de democracia representativa, revela-se 
estratégia importante no processo de democratização e de reordenação do espaço público que tem ocorrido em países como a Bolívia.

Cabe agora utilizar-se o espaço conquistado "desde baixo", e com representatividade política e social promover a efetivação de uma pluralidade normativa a partir da democracia comunitária e do reconhecimento de direitos nascidos de práticas ancestrais, em direção à interculturalidade do Estado Plurinacional Boliviano.

\section{REFERÊNCIAS}

ANDRADE, Vera Regina Pereira de. Cidadania: do Direito aos Direitos Humanos. São Paulo: Acadêmica, 1993.

BERCOVICI, Gilberto. O poder constituinte do povo no Brasil: um roteiro de pesquisa sobre a crise constituinte. Lua Nova, São Paulo, 88: 305-325, 2013. . Constituição e política: uma relação difícil. Lua Nova, São Paulo, $N^{\circ}$ 61, 2004. Representação política: contribuição para um debate inacabado. Revista do Instituto Brasileiro de Direitos Humanos, v. 3, n. 3, 2002.

Soberania e constituição: para uma crítica do constitucionalismo. São Paulo: Quartier Latin, 2008.

BOLÍVIA. Constitución Política del Estado Plurinacional de Bolivia.2007-2008. Disponível em: <http://www.gacetaoficialdebolivia.gob.bo/edicions/view/NCPE >. Acesso em: 04 ago. 2018.

CAMPILONGO, Celso Fernandes; FARIA, José Eduardo. Representação política e ordem jurídica: os dilemas da democracia liberal. 1987. [s.n.], São Paulo, 1987. Dissertação de mestrado.

COMPARATO, Fábio Konder. Repensar a democracia. In: LIMA, Martonio Mont'Alverne Barreto; ALBUQUERQUE, Paulo Antonio de Menezes (Orgs.). Democracia, direito e política: estudos internacionais em homenagem a Friedrich Müller. Florianópolis: Conceito Editorial, 2006.

DUSSEL, Enrique. 20 teses de política. São Paulo: Expressão Popular, 2007. 184 p.

FAGUNDES, Lucas Machado. Juridicidades insurgentes: elementos para o pluralismo jurídico de libertação latino- americano. 2015. Tese (Doutorado em Direito) - Centro de Ciências Jurídicas, Universidade Federal de Santa Catarina, Florianópolis, 2015. 
LÓPEZ, E. Liliana López. El pluralismo jurídico: uma propuesta paradigmática para repensar el Derecho. umbral, 4, t, 1, 2014, pp. 31-64.

LINERA, Alvaro García. Democracia liberal vs. democracia comunitária. Red Voltaire. 2004. Disponível em: http://www.voltairenet.org/article122845.html. Acesso em: 27 Jul 2018.

MARTINEZ, Alejandro Rosillo. Fundamentos del pluralismo jurídico desde la filosofía de la liberación. Revista Derechos en Acción; no. 2. Verano 2016/2017. Disponível em: http://sedici.unlp.edu.ar/handle/10915/59572. Acesso em: 20 Mai 2018.

MEDICI, Alejandro M. El nuevo constitucionalismo latinoamericano y el giro decolonial: Bolivia y Ecuador. Revista Derecho y Ciencias Sociales, Instituto de Cultura Jurídica y Maestría en Sociología Jurídica, n. 3. p. 3-23, oct. 2010.

. Teoría constitucional y giro decolonial: narrativas y simbolismos de las constituciones Reflexiones a propósito de la experiencia de Bolivia y Ecuador. Otros logos Revista de estudios críticos.

MORAES, José Luis Bolzan de; STRECK Lenio Luiz. Ciência Política e Teoria do Estado. 8. ed. Porto Alegre: Livraria do Advogado, 2013.

MOSCHETTA, Silvia Ozelamo Rigo. Teoria pós-moderna do direito de familia na dimensão do pluralismo jurídico: a intervenção nos conflitos conjugais/convivenciais e parentais por meio da mediação familiar. 2016. Tese. Doutorado em Direito- Universidade Federal de Santa Catarina, Florianópolis, 2016. P. 81-92.

MOTA, Sergio Ricardo Ferreira. Teoria Crítica Latino-Americana: Tributo ao Professor Antonio Carlos Wolkmer. Direito e Crítica: Homenagem Ao Professor Antonio Carlos Wolkmer.

PACO. Félix Patzi. Modelo comunal: propuesta alternativa para salir del capitalismo y del socialismo. La Paz: All Press, 2013.

RADAELLI, Samuel. Constitucionalismo comunitário da alteridade: a experiência andina na perspectiva do pluralismo jurídico e da Filosofia da Libertação. 2017. Tese (Doutorado em Direito) - Centro de Ciências Jurídicas, Universidade Federal de Santa Catarina, Florianópolis, 2017.

SANTOS, Boaventura de Sousa. A difícil democracia: reinventar as esquerdas. São Paulo: Boitempo, 2016.

Boitempo, 2007.

Renovar a teoria crítica e reinventar a emancipação social. São Paulo:

Poderá o direito ser emancipatório? Revista Crítica de Ciências Sociais, 65, Maio 2003: 3-76.

Revista Brasileira de Filosofia do Direito| e-ISSN: 2526-012X| Porto Alegre | v. 4 | n. 2 |

p. $108-127$ | Jul/Dez. 2018 
DALMAU, Rubén Martínez. O processo constituinte venezuelano no marco do novo constitucionalismo latino-americano. In: WOLKMER, Antonio Carlos; MELO, Milena Petters. Constitucionalismo latino-americano: tendências contemporâneas. Curitiba: Juruá, 2013. p.154-168.

VILLORO, Luis. Democracia comunitária. Conferencia dictada el 21 de noviembre del 2006 en el Auditorio Raúl Baillères del ITAM.

WOLKMER, Antonio Carlos. Pluralismo jurídico: fundamentos de uma nova cultura no direito. 4. ed. São Paulo: Saraiva, 2001.

Introdução ao pensamento jurídico crítico. 9. ed. São Paula: Saraiva, 2015.

. Da constitucionalidade clássica da representação para os novos caminhos da teoria democrática participativa. REVISTA DO CURSO DE DIREITO, UFMA, São Luís, Ano IV, n. 8, jul/dez 2014.

.Estado Plurinacional, Descolonización y Pluralismo Jurídico Igualitario.

Lima, 5-7 de diciembre 2016, VIII Seminario Internacional y Pre-congreso de la Red latinoamericana de antropología jurídica (RELAJU)- Sección Perú

; MELO, Milena Petters. Constitucionalismo latino-americano: tendências contemporâneas. Curitiba: Juruá, 2013. pp.154-168.

; ALMEIDA, M. C. Elementos para a descolonização do constitucionalismo na América Latina: o pluralismo jurídico comunitário-participativo na Constituição boliviana de 2009. Crítica Jurídica, v. 35, p. 23-44, 2013.

FERRAZZO, D. Resignificação do conceito de democracia a partir de direitos plurais e comunitários latino-americanos. Revista de Direitos Fundamentais e Democracia, Curitiba, v. 16, n. 16, p. 200-228, julho/dezembro de 2014.

; FREITAS, Raquel Coelho de. O impacto do novo constitucionalismo nos processos de construção da democracia na América Latina. Revista da Faculdade de Direito da Universidade Federal de Minas Gerais, v.70, p. 595-632, 2017. 